\title{
Reasons for Drinking Alcohol and Their Relation to Sexual Behaviours among Young Portuguese People
}

\author{
Marta Reis 1,2,3*, Gina Tomé1,2,4, Lúcia Ramiro1,2, Fábio Botelho Guedes1,2, \\ Margarida Gaspar de Matos ${ }^{1,2}$
}

${ }^{1}$ Faculdade de Motricidade Humana (Equipa Aventura Social), Universidade de Lisboa, Lisboa, Portugal

${ }^{2}$ Instituto de Saúde Ambiental, Faculdade de Medicina, Universidade de Lisboa, Lisboa, Portugal

${ }^{3}$ Bolseira Pós-Doutoramento FCT SFRH/BPD/110905/2015, Lisboa, Portugal

${ }^{4}$ Bolseira Pós Doutoramento FCT SFRH/BPD/108637/2015, Lisboa, Portugal

Email: *mreis@fmh.ulisboa.pt

How to cite this paper: Reis, M., Tomé, G., Ramiro, L., Guedes, F. B., \& de Matos, M. G. (2021). Reasons for Drinking Alcohol and Their Relation to Sexual Behaviours among Young Portuguese People. Open Journal of Social Sciences, 9, 12-28.

https://doi.org/10.4236/jss.2021.98002

Received: June 15, 2021

Accepted: July 31, 2021

Published: August 3, 2021

Copyright $\odot 2021$ by author(s) and Scientific Research Publishing Inc. This work is licensed under the Creative Commons Attribution International License (CC BY 4.0)

http://creativecommons.org/licenses/by/4.0/

\begin{abstract}
Alcohol consumption is considered one of the factors with the greatest impact on health. In turn, the use/abuse of alcohol also presents itself as one of the main factors responsible for the involvement in sexual risk behaviours by young people. Therefore, understanding the main reasons that lead young people to consume alcohol is essential to invest in promoting their health and preventing sexual risk behaviours. This paper aims to study the validation of the Portuguese version of the DMQ-R SF in young people aged between 18 and 24 years old and to understand whether the reasons for drinking alcohol are associated with sexual risk behaviours and characteristics of groups of young people. The study includes 1166 young people, with an average age of 21.1 years $(\mathrm{SD}=1.92), 72.3 \%$ being female. Most participants reported having drunk alcohol in the last 12 months (78.4\%) and having had sexual intercourse (89.6\%). More than one third of the participants reported having had sexual intercourse under the influence of alcohol or other drugs (39.2\%) and $23.5 \%$ reported having occasional sexual partners. The reasons for drinking alcohol can be broken down into four types, namely personal satisfaction (enjoyment), social reasons (socialization), social integration (peer pressure), and reasons for dealing with uneasy situations or to overcome difficulties and relieve feelings that generate unease (coping). Regarding sexual behaviours, a significant relationship was found between the reasons for drinking alcohol and the two previously mentioned sexual risk behaviours, suggesting the need for the development of public policies aimed at education and health promotion of young people, including the implementation of educational practices in the academic environment, in the community and in health units.
\end{abstract}




\section{Keywords}

Alcohol Consumption, Reasons for Drinking Alcohol, Sexual Behaviours, Youth, Health Promotion

\section{Introduction}

There is evidence in the literature that points to the stage of adolescence and youth as life stages directly associated with involvement in risk behaviours (MacArthur, Harrison, Caldwell, Hickman, \& Campbell, 2016; Reis et al., 2015). Alcohol consumption, for example, is considered one of the factors with the greatest impact on health, both physically and psychologically as well as socially (Simões, Branquinho, Santos, \& Matos, 2017; Tsoumakas et al., 2014).

According to the latest World Health Organization report (WHO, 2018), alcohol consumption in young people between 15 and 24 years of age has been steadily increasing throughout Europe and prevalence rates in this particular age group are among the highest compared to the total population.

Several studies also concentrate on the fact that increased alcohol consumption symbolises a danger to young people's healthy development and can cause damage at the neurocognitive level (such as learning disabilities), as their bodies are not mature enough to metabolise alcohol, which could compromise their academic career (Brown, Tapert, Granholm, \& Delis, 2000; Lopez-Caneda, Holguín, Cadaveira, Corral, \& Doallo, 2014).

In turn, the use/abuse of alcohol presents itself as one of the main causes of youth involvement in sexual risk behaviours: multiple sexual partners, occasional partners, non-use of condoms, resulting in increased exposure to sexually transmitted infections and unwanted pregnancy (Griffin, Botvin, \& Nichols, 2006; Liu et al., 2006; Ramiro, Reis, Matos, \& Diniz, 2014; Reis, Ramiro, Camacho, Tomé, \& Matos, 2018).

The relation between unprotected sex and alcohol use seems to be affected by the amount of alcohol consumed, interfering in the elaboration of judgment, inhibition, and evaluation of consequences in an anticipated manner. As for the pattern of consumption, young people, when they drink, tend to do so excessively. Although heavy, episodic, or continuous drinking, before or during sexual behaviour, is associated with higher rates of adoption of risky sexual behaviour, moderate drinking has also been shown to be related to unsafe sex (Bailey, Bartholow, Saults \& Lust, 2014; Bell, Rodd, Engleman, Toalston \& McBride, 2014; Ramiro, Reis, Matos, \& Diniz, 2014; Reis, Ramiro, Matos, \& Diniz, 2013).

While adolescence and young adulthood have often been characterized as a time of increased experimentation and exploration with a range of risk behaviours, is also a period of discovery, fun and achievement, and it can sometimes be a confusing time for some young people (MacArthur et al., 2016).

It is also important to understand that adolescence is also a time of happiness, 
experimentation, celebration and fun and just as adults derive pleasure from alcohol consumption, so can young people. Sharing a drunk time with friends can be a bonding experience. It can heighten a sense of group membership and belonging (Tomé, Camacho, Matos, \& Simões, 2015). Risk-taking is also a normal part of development and experimenting alcohol is just one of the many risks that some young people will take during this time of great change.

A wide range of literature supports the assumption that substance use behaviours are driven by different needs, such as socializing with friends or escaping negative mood, that result in diverse consequences (Cooper, Kuntsche, Levitt, Barber, \& Wolf, 2016).

International (Kuntsche \& Kuntsche, 2009) and national (Simões et al., 2017; Reis et al., 2020) studies with adolescents and young people on the reasons for drinking alcohol, reiterate this association of substance use with other risk behaviours, and which jeopardize well-being and health.

The Health Behaviour in School-Aged Children study (HBSC/WHO) conducted in 2018 in Portugal across 6th, 8th and 10th grade students revealed that the majority of young people does not regularly drink alcoholic beverages. However, $3.7 \%$ of young people report consuming spiritual drinks almost every day, while $3.7 \%$ mention consuming beer and 3.5\% wine as frequently. Regarding the behaviour of having sexual intercourse associated with the consumption of substances, it was found that $15.7 \%$ of young people said they had this risk behaviour. Adolescent boys show the highest level of alcohol consumption and the majority of them claim to have a sexual risk practice (Matos \& Equipa Aventura Social, 2018).

In another study on health behaviours, conducted nationally with university students in Portugal, between 18 and 35 years old, it was found that about half of the young people reported drinking 3 to 9 times during the last 30 days (46.4\%) and most of the young people reported being drunk 1 to 2 times during the last 30 days (71.4\%). And as for having sexual intercourse associated with the consumption of alcohol or drugs, $12.2 \%$ reported having done so. No differences were found between men and women regarding the frequency of alcohol consumption, drunkenness and having sexual intercourse associated with the consumption of alcohol or drugs (Reis \& Matos, 2017).

Thus, on the one hand, there is a need to reflect on the reasons that lead young people to experiment and consume alcohol, and on the other hand, it becomes relevant to know the relationship between the consumption of alcohol and the sexual risk behaviours of young people and their consequences for the implementation of public policies to prevent and combat the consumption of alcoholic beverages in this stage of growth and development. Bertholet, Murphy, Daeppen, Gmel and Gaume (2015) emphasize that one of the main causes of consumption is due to the media's call for alcohol consumption and easy access to alcoholic beverages, which is still occurring today, despite all the legal impositions that exist. Another cause of consumption is related to socialization and integration in 
the peer group (Simões et al., 2017) as some young people end up assuming the behaviours of the group, by social learning, which presents itself as a negative element, being important to take into account friends who are part of the group, for a better understanding of the influence exercised (Tomé et al., 2015).

In turn, parents and peers can play a protective and/or risky role in young people's development. A study by Cerqueira, Gaspar, Guedes, Madeira and Matos (2019) reveals that the influence of the relationship with the family and peers is directly associated with the level of well-being and adjustment, as well as the decrease in risk behaviours.

The main goal of this study is to understand whether the reasons for drinking alcohol are associated with sexual risk behaviours and characteristics of youth groups by applying a 12-item scale on reasons to drink alcohol, developed within the international HBSC study (Kuntsche et al., 2014) and used in Portugal in 2010 within HBSC 2010 for adolescents (Matos \& Equipa Aventura Social, 2010; Simões et al., 2017), with young people, from 18 to 24 years old. It is also intended to reflect on the main reasons why young people drink alcohol, as well as whether these are associated with characteristics of youth groups and sexual risk behaviours, such as gender, attendance of higher education, sexual intercourse with occasional partners, and sexual intercourse under the influence of alcohol and/or drugs.

\section{Methodology}

\subsection{Procedure}

The national survey "Life without AIDS" aimed to ascertain knowledge, attitudes, beliefs, skills and behaviours of young people regarding HIV/AIDS.

This cross-sectional study was carried out between April and June 2017 with an evaluation protocol that was administered to young people. All Portuguese universities, both public and private, were invited to participate and the partners of this study-SCHOOL and IPDJ-also invited all young people between the ages 18 and 24 to participate in it. In a first phase, and responding to a first contact by e-mail to 21 public and private universities of mainland Portugal and islands; to all university student associations; and contacts made by partners (SCHOOL and IPDJ), 816 young people participated. The contacts were repeated, this time directed directly to university professors, to the Presidents of the Student Associations, and to the partners of the study (SCHOOL and IPDJ) who were responsible for disseminating the study to the young people. In order to protect participants and their anonymity, no information regarding identity was put on the questionnaires. Confidentiality of the data was also guaranteed.

The data collection protocol complied with the ethical guidelines and the consent of the participants was obtained. The study was submitted to the Ethics Committee of Santa Maria Hospital and followed all the guidelines and ethical norms of human research. Because the study preserves anonymity, it does not need the approval of the data protection commission in Portugal. A convenience sample of young people aged between 18 and 24 years was used. 
The instrument included sociodemographic variables, reasons for drinking alcohol, having sexual intercourse, having sexual intercourse with occasional partners, having sexual intercourse under the influence of alcohol and/or drugs, and other issues related to knowledge, attitudes, and behaviours in relation to HIV/AIDS, outside the scope of this study.

\subsection{Participants}

The study involved 1166 young people, with a mean age of 21.1 years old $(\mathrm{SD}=$ 1.92), ranging from 18 to 24 years old, broken down into two groups: the group of young university students $(\mathrm{N}=914 ; 78.4 \%)$, consisting mostly of young people from the university network $(\mathrm{N}=875)$, which also included 30 young people from the SCHOOL network together with 9 from the IPDJ network; and the group of young non-university students $(\mathrm{N}=252 ; 21.6 \%)$, consisting mostly of young people from the SCHOOL network $(\mathrm{N}=220)$, along with 32 young people from the IPDJ network. The majority of the participants are Portuguese (96.2\%), female (72.3\%), reported having drunk alcohol (78.4\%) and having had sexual intercourse (89.6\%) in the last 12 months. More than one third of the participants reported having had sexual intercourse under the influence of alcohol or other drugs (39.2\%) and 23.5\% reported having occasional sexual partners (see Table 1).

\subsection{Measures}

The scale on the reasons for drinking alcohol is an instrument that measures the main reasons why alcohol is consumed by young people aged 18 to 24 . The original version of DMQ-R SF (Drinking Motives Questionnaire-Revised Short Form) was created in English as part of the Health Behaviour in School-aged Children-HBSC/WHO study (http://www.hbsc.org/) and each country has translated and backtranslated it into the country's language. The Portuguese version, validated for teenagers, has 12 items (see Table 1), which must be answered using a Likert scale of five points, ranging from 1 (never) to 5 (always). Both the original instrument and the Portuguese version are organized in four dimensions (Enjoyment, Socialization, Peer pressure and Coping). Each dimension is evaluated by a set of 3 items each, and an average score was calculated for each dimension, whereby values can range from 3 to 15 points (Kuntsche \& Kuntsche, 2009; Kuntsche et al., 2014; Matos \& Equipa Aventura Social, 2010; Simões et al., 2017).

The first dimension, enjoyment, expresses reasons related to personal satisfaction and includes items that describe this purpose of self-pleasure (example items: "Because it gives you a good feeling"; and "Because it was fun") (Cronbach's alpha $=.77$ ).

The second dimension, socialization, enunciates the person's social reasons when relating to the environment and includes items that describe this purpose of fun (example items: "Because it helped you to have fun in a party"; and "Because it made social moments more special") (Cronbach's alpha $=.83$ ). 
Table 1. Sample description $(\mathrm{n}=1166)$.

\begin{tabular}{|c|c|c|c|c|c|}
\hline & $N$ & $\%$ & $M$ & $S D$ & $\begin{array}{c}\text { Range. } \\
\text { Min - máx }\end{array}$ \\
\hline Total Sample & 1166 & 100 & & & \\
\hline \multicolumn{6}{|l|}{ Gender } \\
\hline Male & 323 & 27.7 & & & \\
\hline Female & 843 & 72.3 & & & \\
\hline Age & & & 21.14 & 1.92 & $18-24$ \\
\hline \multicolumn{6}{|l|}{ Group } \\
\hline University & 914 & 78.4 & & & \\
\hline Non-university & 252 & 21.6 & & & \\
\hline \multicolumn{6}{|l|}{ Nationality } \\
\hline Portuguese & 1122 & 96.2 & & & \\
\hline Other & 44 & 3.8 & & & \\
\hline \multicolumn{6}{|c|}{ Had alcohol in the last 12 months ${ }^{1}$} \\
\hline Yes & 601 & 78.4 & & & \\
\hline No & 166 & 21.6 & & & \\
\hline \multicolumn{6}{|c|}{ Had sexual intercourse } \\
\hline Yes & 562 & 89.6 & & & \\
\hline No & 65 & 10.4 & & & \\
\hline \multicolumn{6}{|c|}{ Had occacional sexual partners ${ }^{1}$} \\
\hline Yes & 131 & 23.5 & & & \\
\hline No & 427 & 76.5 & & & \\
\hline \multicolumn{6}{|c|}{$\begin{array}{l}\text { Had sexual intercourse under the effect } \\
\text { of alcohol and/or drugs }{ }^{2}\end{array}$} \\
\hline Yes & 220 & 39.2 & & & \\
\hline No & 341 & 60.8 & & & \\
\hline
\end{tabular}

${ }^{1}$ The total numbers differ considering that some participants have not replied to some variables. ${ }^{2}$ only those who admitted having had sexual intercourse.

The third dimension, peer pressure, expresses reasons related to social integration, and includes items that describe social acceptance (example items: "So that you do not feel put aside"; and "For people to like you") (Cronbach's alpha $=.90)$.

The fourth dimension, coping, enunciates people's reasons when dealing with situations such as overcoming difficulties and relieving feelings that generate unease and includes items like: "In order to forget your problems" and "In order to cheer yourself up when you were feeling down" (Cronbach's alpha $=.91$ ).

Sexual risk behaviours have been assessed through two issues-having had occasional sexual partners (yes/no) and having had sexual intercourse under the influence of alcohol and/or drugs (yes/no) in the past 12 months (see Table 2 and Table 3). 
Table 2. Description of the variables included in the study $(n=1166)$.

\begin{tabular}{|c|c|c|}
\hline Study variables & Coding & Alpha de Cronbach \\
\hline Gender & $1=$ Male $2=$ Female & - \\
\hline Age & Between 18 and 24 years old & - \\
\hline Group & $\begin{array}{l}1=\text { University } \\
2=\text { Non-university }\end{array}$ & - \\
\hline Nationality & $1=$ Portuguese $; 2=$ Other & - \\
\hline Had alcohol in the last 12 months & $1=\mathrm{Yes} ; 2=\mathrm{No}$ & - \\
\hline Had sexual intercourse & $1=\mathrm{Yes} ; 2=\mathrm{No}$ & - \\
\hline Had occacional sexual partners & $1=$ Yes $; 2=$ No & - \\
\hline $\begin{array}{l}\text { Had sexual intercourse under the effect of } \\
\text { alcohol and/or drugs }\end{array}$ & $1=$ Yes; 2 = No & - \\
\hline \multicolumn{3}{|l|}{ Reasons for drinking alcohol } \\
\hline $\begin{array}{l}\text { Enjoyment } \\
\text { - Because it gives you a good feeling } \\
\text { - To feel drunk } \\
\text { - Because it was fun }\end{array}$ & $\begin{array}{l}1=\text { Never } 2=\text { rarely; } \\
3=\text { sometimes; } 4=\text { often; } \\
5=\text { always }\end{array}$ & .77 \\
\hline $\begin{array}{l}\text { Socialization } \\
\text { - Because it helped you to have fun in a party } \\
\text { - Because it made social moments more special } \\
\text { - Because it promoted fun and parties }\end{array}$ & $\begin{array}{l}1=\text { Never } 2=\text { rarely; } \\
3=\text { sometimes } 4=\text { often; } \\
5=\text { always }\end{array}$ & .83 \\
\hline $\begin{array}{l}\text { Peer pressure } \\
\text { - In order to make part of a group you like } \\
\text { - For people to like you } \\
\text { - So that you do not feel put aside }\end{array}$ & $\begin{array}{l}1=\text { Never } 2=\text { rarely; } \\
3=\text { sometimes } 4=\text { often; } \\
5=\text { always }\end{array}$ & .90 \\
\hline Coping & & \\
\hline $\begin{array}{l}\text { - Because it helped you when you felt depressed } \\
\text { or uptight } \\
\text { - In order to cheer yourself up when you were } \\
\text { feeling down } \\
\text { - In order to forget your problems }\end{array}$ & $\begin{array}{l}1=\text { Never } 2=\text { rarely; } \\
3=\text { sometimes } 4=\text { often } \\
5=\text { always }\end{array}$ & .91 \\
\hline
\end{tabular}

Table 3. Questions of the revised short form of the Reasons for drinking alcohol.

\begin{tabular}{ll}
\hline Dimensions & Questions \\
\hline Enjoyment & Q43.2d. Because it gives you a good feeling \\
& Q43.2e. To feel drunk \\
& Q43.2a. Because it helped you to have fun in a party \\
Socialization & Q43.2f. Because it made social moments more special \\
& Q43.2h. Because it promoted fun and parties \\
Peer pressure & Q43.2k. In order to make part of a group you like \\
& Q43.2l. So that you do not feel put aside \\
Coping & Q43.2b. Because it helped you when you felt depressed or uptight \\
& Q43.2i. In order to forget your problems
\end{tabular}




\subsection{Data Analysis}

The data was analysed using SPSS version 24. For data analysis, internal consistency was assessed by a Cronbach's Alpha test, a correlation analysis, a comparison of means between gender, groups and sexual risk behaviours, using the ANOVA test. To perform the confirmatory factor analysis, we used the structural equation modelling (SEM), through the statistical program EQS, Structural Equation Modeling Software, version 6.1.

\section{Results}

\subsection{Analysis of Internal Consistency}

A factorial structure of 4 dimensions was obtained for the revised short form of the Reasons for drinking alcohol, with good internal consistency for all 4 factors, with values between $\alpha=.77$ in Enjoyment and $\alpha=.91$ in Coping, as well as for the total of the scale $(\alpha=.89)$ (see Table 4$)$.

\subsection{Confirmatory Factorial Analysis}

A confirmatory factorial analysis indicated that the model that was proposed for the scale was adequate (see Table 5). The results obtained in the Wald test did not reveal the existence of non-significant relations (Bentler, 1995, 2008). Therefore, no changes were made to the initial model, which showed good levels of adjustment and good adequacy (see Table 4).

The standardized solution obtained in the confirmatory factor analysis model (Figure 1) shows that, in general, the independent factor has a good saturation in the dependent factors that vary between $\beta=.39$ and $\beta=.96$.

The explained variance of the factors, as well as the residuals, regarding the confirmatory factor analysis model are presented in Table 6. As one can see, these values are equally adequate and vary between $\mathrm{R} 2=.53$ and $\mathrm{R} 2=.91$ (Table $6)$.

Table 4. Revised short form of the Reasons for drinking alcohol-Internal factors consistency.

\begin{tabular}{cccccc}
\hline Factor & Items & $\mathrm{N}^{1}$ & $\boldsymbol{M}$ & $\boldsymbol{S D}$ & Cronbach \\
\hline Total Scale & 12 & 601 & 25.09 & 8.682 & .89 \\
Enjoyment & 3 & 601 & 7.59 & 3.002 & .77 \\
Socialization & 3 & 601 & 8.19 & 3.145 & .83 \\
Peer pressure & 3 & 601 & 4.25 & 2.288 & .90 \\
Coping & 3 & 601 & 5.07 & 2.830 & .91
\end{tabular}

${ }^{1}$ Only young people who admitted having had alcohol in the last 12 months $(n=601)$.

Table 5. Revised short form of the Reasons for drinking alcohol - Adjusted values of the confirmatory factor analysis.

\begin{tabular}{cccccc}
\hline & $\chi^{2}$ (d.f.) & CFI & NNFI & RMSEA (90\% I.C.) $)^{2}$ & SRMR \\
\hline Step 1 & $4537.61(66)$ & .94 & .92 & $.088(.078-.098)$ & .089 \\
\hline
\end{tabular}


Table 6. Revised short form of the Reasons for drinking alcohol-Explained variance $\left(\mathrm{R}^{2}\right)$ and Residual error (Disturbance) of dependent factors-Confirmatory factor analysis.

\begin{tabular}{ccc}
\hline & Confirmatory Factor Analysis I & \\
\hline Factor & $\mathbf{R}^{2}$ & Disturbance \\
\hline Enjoyment & .91 & .30 \\
Socialization & .87 & .37 \\
Peer pressure & .55 & .92 \\
Coping & .53 & .87 \\
\hline
\end{tabular}

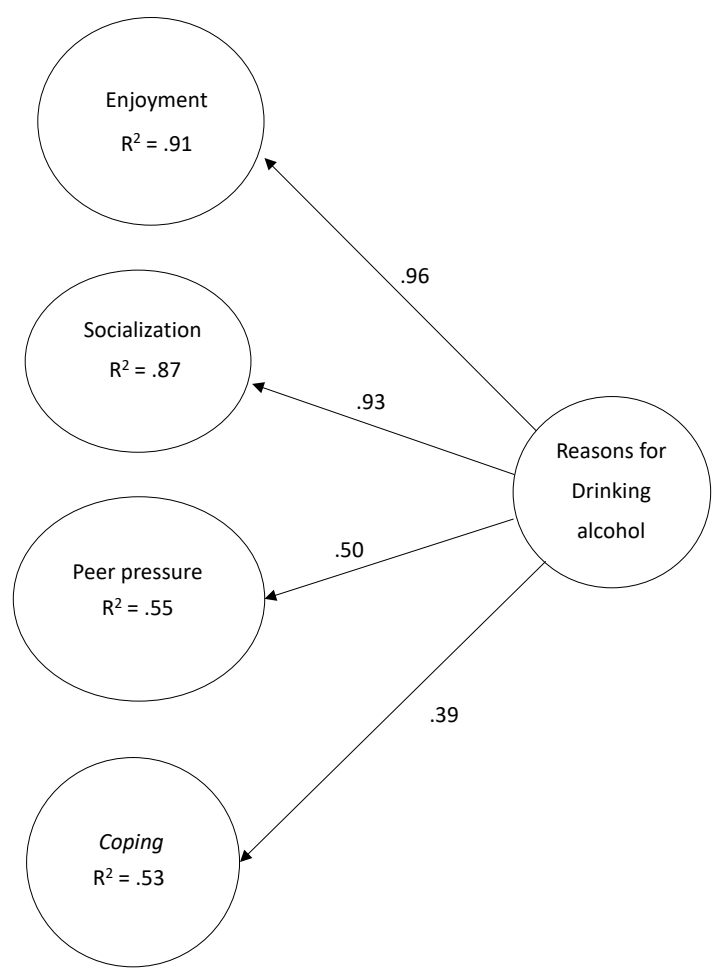

Figure 1. Confirmatory factor analysis.

\subsection{Correlations}

The correlations between the four dimensions of the revised short form of the Reasons for drinking alcohol range from .31 to .74 (see Table 7).

\subsection{Differences between Averages}

We analysed the gender and group differences (university vs. non university students; having had sexual intercourse with occasional partners vs. not having had sexual intercourse with occasional partners; having had sexual intercourse under the influence of alcohol and/or drugs vs not having had sexual intercourse under the influence of alcohol and/or drugs) in the total scale and in the four factors (enjoyment, socialization, peer pressure and coping) by means of the ANOVA tests. In Table 8 and Table 9 the highest average values (with statistical significance) are highlighted in bold. 
Table 7. Correlation between factors of the revised short form of the Reasons for drinking alcohol.

\begin{tabular}{ccccc}
\hline & Enjoyment & Socialization & Peer pressure & Coping \\
\hline Enjoyment & -- & $.74^{* *}$ & $.31^{\star *}$ & $.45^{\star *}$ \\
Socialization & -- & -- & $.35^{\star *}$ & $.39^{\star *}$ \\
Peer pressure & -- & -- & -- & $.41^{\star *}$ \\
Coping & -- & -- & -- & -- \\
\hline
\end{tabular}

${ }^{* *} p<.010$.

Table 8. Revised short form of the Reasons for drinking alcohol-ANOVAS-Differences between Gender and the Group University Vs. Non-university students.

(a)

\begin{tabular}{|c|c|c|c|c|c|c|c|}
\hline & Gender $^{1}$ & Minimum & Maximum & Mean & $\begin{array}{l}\text { Standard } \\
\text { Deviation }\end{array}$ & $\mathrm{F}$ & $p$ \\
\hline \multirow{2}{*}{ Total Scale } & Female & 12 & 55 & 24.23 & 8.155 & \multirow{2}{*}{17.152} & \multirow{2}{*}{.000} \\
\hline & Male & 12 & 55 & 27.53 & 9.641 & & \\
\hline \multirow{2}{*}{ Subscale Enjoyment } & Female & 3 & 15 & 7.41 & 2.984 & \multirow{2}{*}{6.142} & \multirow{2}{*}{.013} \\
\hline & Male & 3 & 15 & 8.10 & 3.004 & & \\
\hline \multirow{2}{*}{ Subscale Socialization } & Female & 3 & 15 & 7.97 & 3.139 & \multirow{2}{*}{8.430} & \multirow{2}{*}{.004} \\
\hline & Male & 3 & 15 & 8.81 & 3.089 & & \\
\hline \multirow{2}{*}{ Subscale Peer pressure } & Female & 3 & 15 & 4.01 & 1.974 & \multirow{2}{*}{19.541} & \multirow{2}{*}{.000} \\
\hline & Male & 3 & 15 & 4.94 & 2.904 & & \\
\hline \multirow{2}{*}{ Subscale Coping } & Female & 3 & 15 & 4.85 & 2.619 & \multirow{2}{*}{10.346} & \multirow{2}{*}{.001} \\
\hline & Male & 3 & 15 & 5.69 & 3.287 & & \\
\hline
\end{tabular}

(b)

\begin{tabular}{|c|c|c|c|c|c|c|c|}
\hline & Group $^{1}$ & Minimum & Maximum & Mean & $\begin{array}{l}\text { Standard } \\
\text { Deviation }\end{array}$ & $\mathbf{F}$ & $p$ \\
\hline \multirow{2}{*}{ Total Scale } & University students & 12 & 55 & 24.57 & 7.925 & \multirow{2}{*}{8.997} & \multirow{2}{*}{.003} \\
\hline & Non-university students & 12 & 55 & 27.22 & 11.026 & & \\
\hline \multirow{2}{*}{$\begin{array}{c}\text { Subscale } \\
\text { Enjoyment }\end{array}$} & University students & 3 & 15 & 7.59 & 2.947 & \multirow{2}{*}{.004} & \multirow{2}{*}{.949} \\
\hline & Non-university students & 3 & 15 & 7.57 & 3.227 & & \\
\hline \multirow{2}{*}{$\begin{array}{c}\text { Subscale } \\
\text { Socialization }\end{array}$} & University students & 3 & 15 & 8.16 & 3.150 & \multirow{2}{*}{.045} & \multirow{2}{*}{.832} \\
\hline & Non-university students & 3 & 15 & 8.30 & 3.137 & & \\
\hline \multirow{2}{*}{$\begin{array}{c}\text { Subscale } \\
\text { Peer pressure }\end{array}$} & University students & 3 & 15 & 4.05 & 1.926 & \multirow{2}{*}{19.782} & \multirow{2}{*}{.000} \\
\hline & Non-university students & 3 & 15 & 5.08 & 3.263 & & \\
\hline \multirow{2}{*}{$\begin{array}{c}\text { Subscale } \\
\text { Coping }\end{array}$} & University students & 3 & 15 & 4.77 & 2.544 & \multirow{2}{*}{27.902} & \multirow{2}{*}{.000} \\
\hline & Non-university students & 3 & 15 & 6.27 & 3.541 & & \\
\hline
\end{tabular}

${ }^{1}$ Only young people that admitted to have had alcohol in the last 12 months $\left.(\mathrm{n}=601)\right|^{*} p \leq .05 ;{ }^{* *} p \leq .01$; ${ }^{* * *} p \leq .001$.

Significant gender differences were found for the total scale $\left(\mathrm{F}_{(1,599)}=17.152 ; p\right.$ $=.000)$ and for the four dimensions-enjoyment $\left(\mathrm{F}_{(1,599)}=6.142 ; p=.013\right)$, so- 
cialization $\left(\mathrm{F}_{(1,599)}=8.430 ; p=.004\right)$, peer pressure $\left(\left(\mathrm{F}_{(1,599)}=19.541 ; p=.000\right)\right.$ and coping $\left(\mathrm{F}_{(1,599)}=10.346 ; p=.001\right)$. In all cases, men had higher averages to drink alcohol than women.

Significant differences were found between groups (university vs. non-university students) in 2 dimensions [peer pressure $\left(\mathrm{F}_{(1,599)}=19.782 ; p=.000\right)$ and coping $\left.\left(\mathrm{F}_{(1,599)}=27.902 ; p=.000\right)\right]$ and for the total scale $\left(\mathrm{F}_{(1,599)}=8.997 ; p\right.$ $=.003)$. In all cases, non-university young people had higher averages in all reasons to drink alcohol than non-university young people.

Significant group differences were found (having had sexual intercourse with occasional partners Vs. not having had sexual intercourse with occasional partners; having had sexual intercourse under the influence of alcohol and/or drugs Vs. not having had sexual intercourse under the influence of alcohol and/or drugs) for the total scale $\left(\mathrm{F}_{(1,443)}=27.397, p=.000 ; \mathrm{F}_{(1,446)}=62.142, p=.000\right.$, respectively) and for the four dimensions-enjoyment $\left(\mathrm{F}_{(1,443)}=25.591, p=.000\right.$; $\mathrm{F}_{(1,446)}=66.922, p=.000$, respectively), socialization $\left(\mathrm{F}_{(1,443)}=17.833, p=.000\right.$; $\mathrm{F}_{(1,446)}=56.197, p=.000$, respectively), peer pressure $\left(\mathrm{F}_{(1,443)}=9.454, p=.002\right.$; $\mathrm{F}_{(1,446)}=5.095, p=.024$, respectively) and coping $\mathrm{F}_{(1,443)}=11.588, p=.001 ; \mathrm{F}_{(1,446)}$ $=25.798, p=.000$, respectively).

In all cases, young people who reported having had sexual intercourse with occasional partners and having had sexual intercourse under the influence of alcohol and/or drugs had higher averages in all reasons to drink alcohol than those who had not had sexual intercourse either with occasional partners or under the influence of alcohol and/or drugs (Table 9).

Table 9. Revised short form of the Reasons for drinking alcohol-ANOVAS-Group differences-Having had sexual intercourse with occasional partners Vs. Not having had sexual intercourse with occasional partners; Having had sexual intercourse under the effect of alcohol and/or drugs Vs. Not having had sexual intercourse under the effect of alcohol and/or drugs.

(a)

\begin{tabular}{cccccccc}
\hline & Group & Minimum & Maximum & Mean & $\begin{array}{c}\text { Standard } \\
\text { Deviation }\end{array}$ & F & $\boldsymbol{p}$ \\
\hline \multirow{2}{*}{ Total Scale } & Yes & 12 & 55 & $\mathbf{2 9 . 1 9}$ & 9.974 & & \\
& No & 12 & 55 & 24.31 & 7.765 & 27.396 & .000 \\
Subscale & Yes & 3 & 15 & $\mathbf{9 . 0 2}$ & 3.072 & & \\
Enjoyment & No & 3 & 15 & 7.40 & 2.799 & 25.591 & .000 \\
Subscale & Yes & 3 & 15 & 9.47 & 2.889 & & \\
Socialization & No & 3 & 15 & 8.02 & 3.094 & 17.833 & .000 \\
Subscale Peer & Yes & 3 & 15 & 4.71 & 2.991 & & \\
pressure & No & 3 & 15 & 3.97 & 1.835 & & .002 \\
Subscale & Yes & 3 & 15 & 5.99 & 3.380 & & \\
Coping & No & 3 & 15 & 4.91 & 2.627 & & .001 \\
\hline
\end{tabular}

${ }^{1}$ Only young people that admitted having had alcohol and having had sexual intercourse in the last 12 months $(\mathrm{n}=448) ;{ }^{2}$ Group $=$ Having had sexual intercourse with occasional partners Vs. Not having had sexual intercourse with occacional partners $\mid{ }^{*} p \leq .05 ;{ }^{* *} p \leq .01 ;{ }^{* * *} p \leq .001$. 
(b)

\begin{tabular}{cccccccc}
\hline & Group $^{1,2}$ & Minimum & Maximum & Mean & $\begin{array}{c}\text { Standard } \\
\text { Deviation }\end{array}$ & F & $p$ \\
\hline Total Scale & Yes & 12 & 55 & $\mathbf{2 8 . 7 4}$ & 8.551 & & \\
& No & 12 & 55 & 22.72 & 7.605 & 62.142 & .000 \\
Subscale & Yes & 3 & 15 & $\mathbf{8 . 9 3}$ & 2.680 & & \\
Enjoyment & No & 3 & 15 & 6.80 & 2.806 & & \\
Subscale & Yes & 3 & 15 & 9.49 & 2.816 & & \\
Socialization & No & 3 & 15 & 7.41 & 3.011 & & .000 \\
Subscale & Yes & 3 & 15 & 4.40 & 2.605 & & \\
Peer pressure & No & 3 & 15 & 3.94 & 1.732 & & .024 \\
Subscale & Yes & 3 & 15 & 5.91 & 3.102 & & \\
Coping & No & 3 & 15 & 4.57 & 2.478 & & \\
\hline
\end{tabular}

${ }^{1}$ Only young people that admitted having had alcohol and having had sexual intercourse in the last 12 months $(n=448) ;{ }^{2}$ Group = Having had sexual intercourse under the effect of alcohol and/or drugs Vs. Not having had sexual intercourse under the effect of alcohol and/or drugs $\mid{ }^{*} p \leq .05 ;{ }^{* *} p \leq .01 ;{ }^{* *} p \leq .001$.

\section{Discussion}

The prevalence of alcohol consumption in youth is high worldwide (Cerqueira et al., 2019). In the present study, the prevalence of young people who used alcohol in the last 12 months was $78.4 \%$ of the participants.

Regarding the main reasons for drinking alcohol among young people, four reasons are identified, namely personal satisfaction (enjoyment), social reasons (socialization), social integration (peer pressure), and reasons for dealing with uneasy situations or to overcome difficulties and relieve feelings that generate unease (coping) (Kuntsche \& Kuntsche, 2009; Kuntsche et al., 2014; Matos \& Equipa Aventura Social, 2010; Simões et al., 2017).

In the present study, it was our intention to use the factorial structure indicated (with four dimensions) by the authors of the Portuguese version of the DMQ-R SF scale for adolescents (Simões et al., 2017) with young people. Results concluded that the scale showed good internal consistency for all four factors/ dimensions, the dimension most referred to by the participants being Socialization, and the one less referred to is Coping.

In the performance of the factor analysis model, the results obtained regarding the adequacy of the proposed explanatory model showed that it presented good levels of adequacy. Thus, we decided not to make changes to the Portuguese version for adolescents (Simões, Branquinho, Santos, \& Matos, 2017), which showed good levels of adjustment, and therefore, good adequacy.

\section{Reasons for drinking alcohol-Differences between Gender and Groups}

Gender and group differences were found (university and non-university students; whether or not they had sexual intercourse with occasional partners; whether or not they had sexual intercourse under the influence of alcohol and/or drugs, and the reasons for consuming alcohol evaluated by the DMQ-R SF. 
Regarding gender differences and reasons for drinking, significant differences were found for the total scale and the four dimensions-enjoyment, socialization, peer pressure and coping. In all cases, men had higher averages for all reasons to drink alcohol than women. But the reason that scored higher for both men and women was socialization.

As for the differences between university and non-university subjects, significant differences were found in 2 dimensions (peer pressure and coping) and for the total scale. In all cases, non-university youth had higher averages in all reasons to drink alcohol than university youth. And the reason with a higher average for both non-university and college students was socialization.

With respect to group differences (having had sexual intercourse with occasional partners or not; having had sexual intercourse under the influence of alcohol and/or drugs or not) and reasons for drinking, significant differences were found for the total scale and the four dimensions-enjoyment, socialization, peer pressure, and coping. In all cases, young people who reported having had sexual intercourse with occasional partners and having had sexual intercourse under the influence of alcohol and/or drugs had higher averages for all reasons to drink alcohol than those who had not had sexual intercourse either with occasional partners or under the influence of alcohol and/or drugs.

The results found in the Portuguese version for young people go in the same direction as those found in the analysis of the original version, as well as the Portuguese version for adolescents (Kuntsche \& Kuntsche, 2009; Simões, Branquinho, Santos, \& Matos, 2017). The Portuguese version for young people, from 18 to 24 years of age, of the DMQ-R SF instrument, maintaining the structure of the original questionnaire and the Portuguese version for adolescents, presents good metric properties and is sensitive to the differences in gender and groups analysed.

Thus, the DMQ-R SF is considered a valid tool in the assessment of the reasons for drinking alcohol among young people aged from 18 to 24, and an important contribution to intervention and research in the field of health promotion and prevention of risk behaviours, namely alcohol consumption and sexual risk behaviours, in several fields of knowledge, from Education to Health.

In relation to sexual behaviour, the vast majority of young people (89.6\%) reported having already had sexual intercourse. The majority of participants did not report having engaged in the two sexual risk behaviours identified in the questionnaire (having sexual intercourse with occasional partners $(23.5 \%)$ and having sexual intercourse under the influence of alcohol and/or drugs (39.2\%)). However, a significant relation was found between the reasons used to consume alcohol and these two sexual risk behaviours.

The results found show that young men, those who reported having had sexual intercourse with occasional partners and those who reported having had sexual intercourse under the influence of alcohol and/or drugs, are the ones who drink more frequently, for the four reasons-enjoyment, socialization, peer pressure, and coping. 
These results show, on the one hand, a relation between alcohol consumption and sexual risk behaviours, and on the other hand, a tendency in drinking alcohol for a multiplicity of reasons and not just one, and that the different reasons relate to each other and are interconnected as a whole.

Another interesting result is that young people who do not attend higher education present peer pressure and coping as the main reasons for drinking, suggesting that young people who are not studying drink more because they have more difficulties in managing peer pressure and more difficulties in overcoming difficulties and regulating unease. These results are reiterated by other studies (Bell et al., 2014; Matos \& Equipa Aventura Social, 2010, 2018; Simões, Branquinho, Santos, \& Matos, 2017).

And although the current law in Portugal (Decree-Law no. 106/2015, of June $16,2015)$ has as its main goal to reduce the access of young people to alcohol, the results reveal that this prohibition is not sufficient, since it only prohibits the access of minors to alcohol and does not foresee young people aged between 18 to 24, a group whose consumption of alcohol is higher. According to WHO (2018), the highest rates of consumption prevalence fall in this age group when compared to the total population.

Knowledge of the interrelationships between alcohol consumption and sexual behaviour of young people is particularly relevant since this group has been identified as an important population group in terms of epidemiological risk for sexually transmitted infections (Reis et al., 2013). In addition, the negative consequences of alcohol misuse constitute a serious public health problem and are even associated with higher road mortality among young people.

\section{Conclusion and Key-Messages}

The results clearly show the need for prevention campaigns to review their approach strategies, focusing on health risk behaviours, especially in relation to the adoption of educational measures for healthy sexual behaviours.

In addition, an alternative to minimize this problem of alcohol abuse by young people would be to try to involve them in healthier activities, such as sports activities or other leisure and relaxation activities (which do not involve the consumption of alcohol or drugs) that are to their liking. It is fundamental that public health policies rethink alternatives so that young people do not turn to alcohol to enjoy themselves and socialize. In addition, there is a need for young people to develop personal and socio-emotional skills, linked, for example, to the development of assertiveness, self-esteem, self-regulation and resilience so that they don't consume alcohol as a result of yielding to peer pressure or not being able to cope with difficulties.

On the other hand, it would be extremely important to consider cultural relevance if some activities carried out in Portugal were to be replicated in the light of the model implemented in Iceland by Milkman (2016), according to which through a set of healthy alternatives the consumption of alcohol and drugs in 
young Icelanders was drastically reduced. This study highlighted, above all, the importance of young people's relationship with their parents (educating parents about the importance of emotional support, parental monitoring and time spent with their children), the powerful influence of the peer group and the commitment to facilitate young people's participation in organized recreational and extracurricular activities. They focused not only on reducing risk factors, but also on mobilizing society to promote responsible guardianship, community attachment and informal social control, all at the local community level.

This intervention program, named Icelandic Substance Use Prevention Model, suggests that the youth who are strongly attached to their parents and family and who participate in recreational and sports activities are significantly less likely to engage in risk behaviours with their peers. It is also important to stress that this approach is not limited to the conventional time framed "program", but it constitutes a long-term effort to change society. The programme has specificities that make it difficult to implement it in other countries, and that will have to be adjusted to different realities, according to the countries (e.g. the "curfew" in the evening, the financial allowance for parents who join the program, the small number of young people in this country).

The importance of family relationships and recreational and extracurricular activities are highlighted as healthy alternatives that promote and replace the main reasons why young people consume alcohol: enjoying themselves, socializing, dealing with everyday difficulties and dealing with peer pressure.

Finally, alcohol consumption and sexual behaviour were associated, suggesting the need for the development of public policies aimed at education and promotion of young people's health with educational practices being introduced in the academic environment, in the community and in health units.

\section{Conflicts of Interest}

The authors declare no conflicts of interest regarding the publication of this paper.

\section{References}

Bailey, K., Bartholow, B. D., Saults, J. S., \& Lust, S. A. (2014). Give Me Just a Little More Time: Effects of Alcohol on the Failure and Recovery of Cognitive Control. Journal of Abnormal Psychology, 123, 152-167. https://doi.org/10.1037/a0035662

Bell, R. L., Rodd, Z. A., Engleman, E. A., Toalston, J. E., \& McBride, W. J. (2014). Scheduled Access Alcohol Drinking by Alcohol-Preferring (P) and High-Alcohol-Drinking (HAD) Rats: Modeling Adolescent and Adult Binge-Like Drinking. Alcohol, 48, 225-234. https://doi.org/10.1016/j.alcohol.2013.10.004

Bentler, P. M. (1995). EQS Structural Equations Program Manual. Multivariate Software.

Bentler, P. M. (2008). EQS 6 Structural Equations Program Manual. Multivariate Software.

Bertholet, N., Murphy, J., Daeppen, J., Gmel, G., \& Gaume, J. (2015). The Alcohol Purchase Task in Young Men from the General Population. Drug and Alcohol Dependence, 146, 39-44. https://doi.org/10.1016/j.drugalcdep.2014.10.024 
Brown, S., Tapert, S., Granholm, E., \& Delis, D. (2000). Neurocognitive Functioning of Adolescents: Effects of Protracted Alcohol Use. Alcoholism: Clinical and Experimental Research, 24, 164-171. https://doi.org/10.1111/j.1530-0277.2000.tb04586.x

Cerqueira, A., Gaspar, T., Guedes, F. B., Madeira, S., \& Matos, M. G. (2019). Sofrimentos psicológico, consumo de tabaco, álcool e outros fatores psicossociais em adolescentes portugueses. Revista de Psicologia da Criança e do Adolescente, 10, 219-228.

Cooper, M. L., Kuntsche, E., Levitt, A., Barber, L. L., \& Wolf, S. (2016). Motivational Models of Substance Use: A Review of Theory and Research on Motives for Using Alcohol, Marijuana, and Tobacco. In K. J. Sher (Ed.), The Oxford Handbook of Substance Use and Substance Use Disorders (Vol. 1, pp. 375-421). Oxford University Press. https://doi.org/10.1093/oxfordhb/9780199381678.013.017

Griffin, K. W., Botvin, G. J., \& Nichols, T. R. (2006). Effects of a School-Based Drug Abuse Prevention Program for Adolescents on HIV Risk Behavior in Young Adulthood. Prevention Science, 7, 103-112. https://doi.org/10.1007/s11121-006-0025-6

Kuntsche, E., \& Kuntsche, S. (2009). Development and Validation of the Drinking Motive Questionnaire Revised Short Form (DMQ-R SF). Journal of Clinical Child \& Adolescent Psychology, 38, 899-908. https://doi.org/10.1080/15374410903258967

Kuntsche, E., Nic Gabhainn, S., Roberts, C. et al. (2014). Drinking Motives and Links to Alcohol Use in 13 European Countries. Journal of Studies on Alcohol and Drugs, 75, 428-437. https://doi.org/10.15288/jsad.2014.75.428

Liu, A., Kilmarx, P., Jenkins, R. A., Manopaiboon, C., Mock, P. A., Jeeyapunt, S. et al. (2006). Sexual Initiation, Substance Use, and Sexual Behavior and Knowledge among Vocational Students in Northern Thailand. International Family Planning Perspectives, 32, 126-135. https://doi.org/10.1363/3212606

Lopez-Caneda, E., Holguín, S., Cadaveira, F., Corral, M., \& Doallo, S. (2014). Impact of Alcohol use on Inhibitory Control (and Vice Versa) during Adolescence and Young Adulthood: A Review. Alcohol and Alcoholism, 49, 173-181. https://doi.org/10.1093/alcalc/agt168

MacArthur, G. J., Harrison, S., Caldwell, D. M., Hickman, M., \& Campbell, R. (2016). Peer-Led Interventions to Prevent Tobacco, Alcohol and/or Drug Use among Young People Aged 11-21 Years: A Systematic Review and Meta-Analysis. Addiction, 111, 391407. https://doi.org/10.1111/add.13224

Matos, M. G., \& Equipa Aventura Social (2010). A saúde dos adolescentes portugueses. Relatório do estudo Health Behaviour in School Aged Children (HBSC) em 2010. http://aventurasocial.com/

Matos, M. G., \& Equipa Aventura Social (2018). A saúde dos adolescentes portugueses após a recessão. Relatório do estudo Health Behaviour in School Aged Children (HBSC) em 2018. https://www.aventurasocial.com/

Milkman, H. B. (2016). Iceland Succeeds at Reversing Teenage Substance Abuse the US Should Follow Suit.

https://www.drugfree.org.au/images/pdf-files/library/iceland/Iceland Succeeds at Rev ersing Teenage Substance Abuse.pdf

Ramiro, L., Reis, M., Matos, M. G., \& Diniz, J. A. (2014). Trends in Adolescent Sexual Behavior, Impact of Information, and Attitudes about HIV/AIDS in Portugal. Psychology, Health \& Medicine, 19, 614-624. https://doi.org/10.1080/13548506.2013.845299

Reis, M., Camacho, I., Ramiro, L., Tomé, G., Gomes, P., Gaspar, T., Canha, L., Simões, C., \& Matos, M. G. (2015). A escola e a transição para a universidade: idades transacionais e o seu impacto na saúde-notas a partir do Estudo HBSC/OMS. Journal of Child and Adolescent Psychology/Revista Psicologia da Criança e do Adolescente, 6, 77-92. 
Reis, M., Matos, M. G., \& equipa Aventura Social (2017). HBSC/JUnP: Comportamentos de Saúde dos Jovens Universitários Portugueses. Aventura Social/FMH/ULisboa/FCT.

Reis, M., Ramiro, L., Camacho, I., Tomé, G., \& Matos, M. G. (2018). Trends in Portuguese Adolescents' Sexual Behavior from 2002 to 2014: HBSC Portuguese Study. Por tuguese Journal of Public Health, 36, 32-40. https://doi.org/10.1159/000486014 https://www.karger.com/Article/FullText/486014

Reis, M., Ramiro, L., Matos, M. G., \& Diniz, J. A. (2013). Nationwide Survey on HIV/ AIDS Knowledge, Attitudes and Risk Behaviour in University Students of Portugal. The Spanish Journal of Psychology, 16, e99. https://doi.org/10.1017/sjp.2013.100

Reis, M., Tomé, G., Ramiro, L., Gaspar, S., \& Matos, M. G. (2020). Understanding Risk Factors Associated with Self-Harm Behavior in Adolescents-HBSC Portuguese Data 2018. International Journal of Humanities Social Sciences and Education, 3, 79-92.

Simões, C., Branquinho, C., Santos, A., \& Matos, M. G. (2017). Motives to Use Alcohol among Adolescents According to Their Neighbourhood Characteristics, Gender, Age, and Drinking Patterns. Journal of Substance Use, 23, 43-48. https://doi.org/10.1080/14659891.2017.1348550

Tomé, G., Camacho, I., Matos, M. G., \& Simoes, C. (2015). Influência da familia e amigos no bem-estar e comportamento de risco-Modelo explicativo. Psicologia, Saude e Doenças, 16, 23-34. https://doi.org/10.15309/15psd160104

Tsoumakas, K., Tanaka, M., Petsios, K., Fildisis, G., Gkoutzivelakis, A., \& Pavlopoulou, I. (2014). Alcohol Drinking Habits and Negative Experiences among Adolescents in Greece. Open Journal of Pediatrics, 4, 222-230.

https://doi.org/10.4236/ojped.2014.43029

World Health Organization, WHO (2018). Global Status Report on Alcohol and Health. WHO Press. 